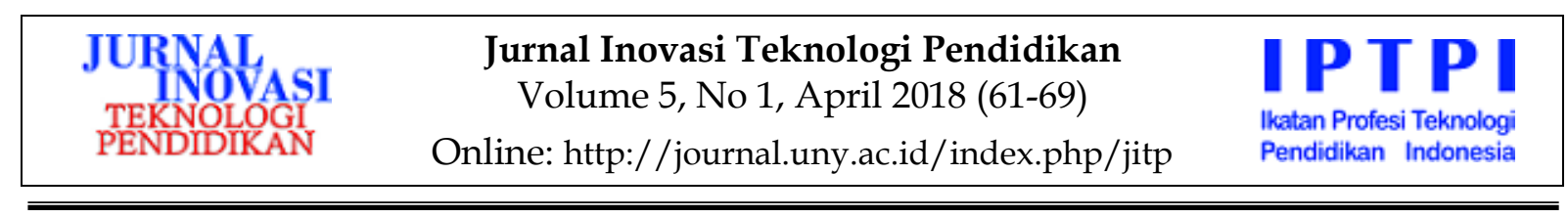

\title{
VISUAL LITERASI MEDIA PEMBELAJARAN BUKU CERITA ANAK
}

\author{
Atin Fatimah ${ }^{1 *}$, Kristiana Maryani ${ }^{1}$ \\ 1 Universitas Sultan Ageng Tirtayasa \\ 1Jalan Raya Jakarta Km 4, Panancangan, Cipocok Jaya, Kota Serang, Banten 42124, Indonesia \\ * Corresponding Author. Email: fatimah.79@untirta.ac.id
}

\begin{abstract}
Abstrak
Tujuan penelitian ini adalah untuk mendapatkan informasi tentang Visual Literacy Media Pembelajaran Buku Cerita Anak Usia 5-6 tahun. Metode yang digunakan dalam penelitian ini adalah survei dan wawancara, buku cerita sebagai sumber penelitian diambil secara acak dari lokasi penelitian dengan jumlah 100 buku dari 828 buku cerita yang tersedia di pusat sumber belajar (PSB) TK Islam Al Azhar Serang. Hasil yang diperoleh dari penelitian ini adalah kualitas gambar visual disajikan dengan sangat baik, kesesuaian visual literasi dengan tujuan pembelajaran, kesesuaian dengan materi, daya tahan buku, kecepatan presentasi materi, disajikan dengan baik dan indikator lainnya menunjukkan hasil yang cukup, yaitu kosakata mudah dipahami anak, penggunaan bahasa yang singkat, padat dan jelas, urutan dan runtut materi, kesesuaian penyajian visual dengan kebutuhan berbagai karakter siswa, prosedur penggunaan, penyajian pedoman untuk guru. Dengan kata lain, pada umumnya visualisasi gambar yang disajikan dalam buku cerita di Pusat Sumber Belajar (PSB) TK Islam Al Azhar 10 Serang telah menunjukkan hasil yang cukup dengan frekuensi kemunculan rata-rata hampir setengahnya.
\end{abstract}

Kata kunci: visual literasi, buku cerita

\section{VISUAL LITERACY INSTRUCTIONAL MEDIA OF CHILDREN'S STORY BOOKS}

\section{Abstract}

This study aim to obtain information about the visual literacy of children's story books of 5-6 years old Children. The method used in this research are survey and interview, story book as sample taken 100 books randomly from 828 story books in learning resource center (PSB) TK Islam Al Azhar Serang. The results of this study are the quality of visual literacy is presented very well, the visual literacy suitability with the aim of learning, material conformity, book endurance, the speed of material presentation are presented well and other indicators show sufficient results, the vocabulary is easy to understand, performed clear sentences, sequence and material coherence, the appropriateness of visual representation with the needs of various student characters, provide procedures and guidelines for teacher. In other words, the conclusion is the visual literacy of the images presented in the storybooks at the Learning Resource Center (PSB) of Al Azhar Islamic Kindegarten School 10 Serang has shown sufficient results with an average occurrence frequency of nearly half.

Keywords: visual literacy, story books

Permalink/DOI: http://dx.doi.org/10.21831/jitp.v5i1.16212 


\section{Pendahuluan}

Salah satu media yang paling sering digunakan oleh guru di dalam kelas adalah buku. Buku memang mampu membawa perubahan dalam sejarah peradaban manusia. Sebelum manusia mengenal dan mencetak buah pikirannya dalam bentuk buku, manusia zaman kuno telah mengenal tulisan dan memproduksi gagasan yang dituangkan di dinding gua.

Dalam perkembangannya, ilmu pengetahuan dituangkan ke dalam buku. Buku yang lahir pertama kali berupa tulisan tangan menjadi penanda berakhirnya tradisi lisan. Melalui tulisan-tulisan dan kitabkitab kuno, manusia membebaskan diri dari berbagai usaha menghafal atau mengingat gagasan, konsep, teori, kisah, adat dan kebiasaan dan kemudian mewariskannya kepada generasi sesudahnya.

Seorang pebelajar dituntut untuk dapat "membaca" isi pesan dalam buku dengan baik tanpa menimbulkan salah persepsi. Kita memerlukan kemampuan untuk menganalisis, membuat, dan menginterpretasi gambar-gambar yang berbicara dalam bahasa visual. Kemampuan ini lebih lazim dikenal dengan istilah visual literacy. Visual Literacy memberi siswa kemampuan untuk secara aktif mengungkap dan mendeskonstruksi kode-kode dari sebuah gambar, dari pada menjadi seorang penerima yang pasif.

Dalam artikel Storey (1984) yang berjudul Reading Comprehension, Visual Literacy And Picture Book Illustrations, bahwa "Illustrations in picture books contribute to a child's sense of story and the visual clues add to the information in the text. Readers need to be aware that there is more to an illustration than meets the eye".

Pada kenyataannya, orang dewasa pun banyak yang belum memahami makna sebuah gambar. Hasil penelitian sebelumnya yang bertajuk parent's visual literacy toward toys symbol menunjukkan bahwa pengetahuan orang tua terhadap symbol-simbol pada kemasan mainan anak-anak mereka tidak mereka pahami, seperti kreativitas, motorik halus, motorik kasar, bahasa, keterampilan sosial, self esteem, thinking skills, dan taktik (Fatimah, 2016, p. 305).

Mengajarkan visual literacy adalah salah satu cara agar siswa mampu menyadari dan kritis terhadap gambar-gambar yang ada di sekeliling kehidupan mereka sehari-hari karena visual literacy memberi siswa kemampuan untuk secara aktif mengungkap dan mendeskonstruksi kode-kode dari sebuah gambar, dari pada menjadi seorang penerima yang pasif.

Dengan demikian maka peneliti melakukan survei mengenai keterbacaan visual dengan tujuan untuk mendapatkan informasi tentang Visual Literacy Media Pembelajaran Buku Cerita Anak Usia 5-6 tahun khususnya dalam hal kesesuaian dengan tujuan pembelajaran, kosakata, isi materi, kebutuhan siswa, dan penggunaan media, baik dari segi prosedur, pedoman guru maupun kualitas gambar/visual.

\section{Metode Penelitian}

Penelitian ini menggunakan metode deskriptif kualitatif dengan mengangkat permasalahan yang terjadi pada saat penelitian dilaksanakan. Metode deskriptif ini dilakukan dengan pertimbangan bahwa dalam penelitian ini tidak diperlukan perlakuan variabel. Melalui metode ini, peneliti bermaksud melakukan survei terhadap kualitas visual literasi buku cerita anak di Pusat Sumber Belajar (PSB) yang terdapat di Taman Kanak-kanak Islam Al Azhar 10 Serang.

Buku cerita anak yang terdapat di Pusat Sumber Belajar TK Islam Al Azhar 10 Serang sebanyak 828 judul buku cerita yang berbeda. Dari populasi yang ada, peneliti mengambil sampel penelitian 100 judul bu$\mathrm{ku}$ cerita anak yang berbeda dan digunakan anak sehari-hari.

Berikut adalah Kisi-kisi instrumen penelitian keterbacaan visual buku cerita anak di TK Islam Al Azhar 10 Serang yang disajikan pada Tabel 1. 
Tabel 1. Kisi-kisi Instrumen

\begin{tabular}{|c|c|c|}
\hline No & Aspek & Indikator \\
\hline 1 & $\begin{array}{l}\text { Kesesuaian visual literacy dengan } \\
\text { tujuan pembelajaran }\end{array}$ & 1. Sesuai dengan tujuan pembelajaran (RKH) \\
\hline \multirow[t]{2}{*}{2} & \multirow[t]{2}{*}{ Kosakata yang disajikan dalam buku } & 2. Kosakata mudah dipahami anak \\
\hline & & 3. Penggunaan bahasa singkat, padat, jelas. \\
\hline \multirow[t]{3}{*}{3} & \multirow{3}{*}{$\begin{array}{l}\text { Kesesuaian visual literacy dengan isi } \\
\text { materi }\end{array}$} & 4. Materi memuat pembuka-isi-penutup \\
\hline & & 5. Materi runtut (dari yang mudah-sulit) \\
\hline & & 6. Kesesuaian materi dengan gambar yang disajikan \\
\hline \multirow[t]{3}{*}{4} & \multirow{3}{*}{$\begin{array}{l}\text { Kesesuaian visual literacy dengan } \\
\text { kebutuhan siswa }\end{array}$} & 7. Sesuai untuk berbagai karakter siswa \\
\hline & & 8. Kemungkinan bertahan lama \\
\hline & & 9. Kecepatan presentasi \\
\hline \multirow[t]{3}{*}{5} & \multirow[t]{3}{*}{ Kualitas penggunaan media } & 10. Prosedur penggunaan \\
\hline & & 11. pedoman guru \\
\hline & & 12. kualitas gambar/visual \\
\hline
\end{tabular}

Pengolahan dan analisis data dalam penelitian ini adalah perhitungan persentase dan chi kuadrat sebagai berikut.

$\%=\frac{(f)}{(n) \times 100}$

Keterangan:

$\mathrm{f}=$ frekuensi

$\mathrm{n}=$ jumlah peserta

Proporsi, yang dinyatakan dalam persen, dengan menggunakan rumus dengan penafsiran sebagaimana disajikan pada Tabel 2.

Tabel 2. Tafsiran Persentase

\begin{tabular}{ccl}
\hline No & $\begin{array}{c}\text { Persentase } \\
(\%)\end{array}$ & Penafsiran \\
\hline 1 & $0-25$ & Sebagian kecil \\
2 & $25-45$ & Hampir setengahnya \\
3 & 50 & Setengahnya \\
4 & $51-75$ & Sebagian besar \\
5 & $76-99$ & Hampir seluruhnya \\
6 & 100 & Seluruhnya \\
\hline
\end{tabular}

Perhitungan selanjutnya adalah analisis Chi-kuadrat yang digunakan dengan tujuan untuk mengetahui apakah terdapat perbedaan yang signifikan antara frekuensi yang diobservasi ( $\mathrm{Fo}$ ) dan frekuensi yang diharapkan/ekspektasi (Fe). Adapun langkah-langkah yang dilakukan adalah sebagai berikut: (a) menghitung jumlah frekuensi observasi pada setiap alternatif jawaban; (b) menghitung jumlah frekuensi ekspektasi pada tiap-tiap alternatif jawaban dengan cara menjumlahkan semua jumlah frekuensi, kemudian dibagi dengan banyaknya alternatif jawaban.

$F e=\frac{\text { Jml Frekuensi }}{\text { Jml Alternatif }}$

Mencari selisih $\mathrm{F}_{\mathrm{o}}$ dan $\mathrm{F}_{\mathrm{e}}$ dengan rumus berikut.

$F_{o}-F_{e}$

Menghitung kuadrat selisih $\mathrm{F}_{\mathrm{o}}-\mathrm{F}_{\mathrm{e}}$ dengan rumus berikut.

$\left(F_{o}-F_{e}\right)^{2}$

Hasil kuadrat selisih tersebut dibagi dengan $\mathrm{F}_{\mathrm{e}}$, sebagai berikut.

$\frac{\left(F_{o}-F_{e}\right)^{2}}{F_{e}}$

Mencari nilai Chi kuadrat hitung dengan rumus berikut.

$X^{2}=\frac{\sum\left(f_{o}-f_{E}\right)^{2}}{f_{E}}$ 
Keterangan:

$X^{2}=$ Chi-kuadrat

$f_{o}=$ Frekuensi yang diamati

$f_{E} \quad=$ Frekueni yang diharapkan

(Sudjana \& Ibrahim, 2001, p. 145)

Menentukan derajat kepercayaan (Dk) dengan cara jumlah alternatif jawaban dikurangi satu: Dk - 1. Menentukan harga kritis Chi kuadrat tabel pada tingkat 95\% dengan menggunakan daftar tabel Chi kuadrat agar dapat diinterpretasikan apakah terdapat perbedaan yang signifikan atau tidak.

Menafsirkan atau menguji hasil perhitungan Chi kuadrat dengan kriteria sebagai berikut:

Jika $\chi^{2} \mathrm{Hit}>\chi^{2} \mathrm{Tab}$, berarti terdapat perbedaan yang signifikan antara frekuensi yang diperoleh dengan frekuensi yang diharapkan.

Jika $\chi^{2}{ }_{\text {Hit }}<\chi^{2}$ Tab, maka pengujian tidak berarti dan tidak terdapat perbedaan yang signifikan antara frekuensi yang diperoleh dengan frekuensi yang diharapkan.

\section{Hasil Penelitian dan Pembahasan}

Pembahasan ini merupakan hasil mengkaji pertanyaan penelitian dan tujuan penelitian dengan melihat temuan pada deskripsi hasil penelitian. Hasil penelitian menunjukkan bahwa penilaian terhadap visual literasi buku cerita di pusat sumber belajar TK Islam Al Azhar 10 Serang pada umumnya adalah cukup baik.
Hasil penelitian (Storey, 1984) bahwa sebuah ilustrasi pada buku bergambar sangat berkontribusi pada pemahaman anak yang melihatnya agar anak mendalami makna dan rasa dari suatu cerita. Gambar tidak sekedar berbicara visual, namun juga memiliki pengaruh untuk memperkuat informasi agar sampai dan dipahami oleh pembaca. Saat pembaca baik anak maupun orang dewasa menyadari hal tersebut, maka sesungguhnya pembaca telah memiliki kemampuan "membaca gambar" atau visual literasi dengan sangat baik. Sejalan dengan hasil penelitian Visual Literasi Buku Cerita Anak, hasil pengamatan terhadap 100 judul buku sampel yang berbeda menunjukkan data frekuensi observasi bahwa kualitas gambar visual buku cerita di pusat sumber belajar TK Islam Al Azhar 10 Serang secara umum adalah sangat baik.

Salah satu indikator dari penelitian ini mengkaji tentang kualitas gambar visual sebagai bagian dari aspek kualitas media. Data hasil penelitian yang diperoleh penelitian ini disajikan pada Tabel 3.

Dari Table 3 didapatkan hasil bahwa $\chi^{2}{ }_{h} 62.5>\chi^{2}$ 9.49 dengan Dk 5 - 1 pada tingkat kepercayaan 95\%. Hal ini berarti terdapat perbedaan yang signifikan antara frekuensi yang diperoleh dengan frekuensi yang diharapkan. Sehingga dengan demikian dapat diinterpretasikan bahwa sebanyak $41 \%$ (hampir setengahnya) hasil pengamatan terhadap 100 judul buku yang berbeda menyatakan bahwa kualitas gambar visual buku cerita di pusat sumber belajar TK Islam Al Azhar 10 Serang secara umum adalah sangat baik.

Tabel 3. Kualitas Gambar Visual

\begin{tabular}{lccccccc}
\hline Alternative Choice & $\mathrm{F}_{\mathrm{o}}$ & $\%$ & $\mathrm{~F}_{\mathrm{e}}$ & $\mathrm{F}_{\mathrm{o}}-\mathrm{F}_{\mathrm{e}}$ & $\left(\mathrm{F}_{\mathrm{o}}-\mathrm{F}_{\mathrm{e}}\right)^{2}$ & $\frac{\left(\mathrm{F}_{\mathrm{o}}-\mathrm{F}_{\mathrm{e}}\right)^{2}}{\mathrm{~F}_{\mathrm{e}}}$ & $\square{ }^{2}$ \\
\hline Sangat baik & 41 & 41.00 & 20 & 21 & 441 & 22.05 & 62.5 \\
Baik & 23 & 23.00 & 20 & 3 & 9 & 0.45 & \\
Cukup & 32 & 32.00 & 20 & 12 & 144 & 7.2 & $\mathrm{dk} 5-1$ \\
Kurang & 4 & 4.00 & 20 & -16 & 256 & 12.8 & $95 \%$ \\
Sangat Kurang & 0 & 0.00 & 20 & -20 & 400 & 20 & 9.49 \\
\hline \multicolumn{1}{c}{ Total } & 100 & 100 & 100 & & & 62.5 & \\
\hline
\end{tabular}


Shambaugh \& Beacham (2017, pp. 1-19) dalam artikel "Visual Guidebooks: Documenting A Personal Thinking Language" menyatakan, "This verbal and visual interaction of images and language is influenced by one's personal history, cultural expectations and professional practices". Dengan kata lain, interaksi antara bahasa verbal dan visual dalam penyajian gambar dan narasi (teks bahasan) dalam sebuah buku cerita dipengaruhi oleh latar belakang pribadi seseorang, nilai-nilai sosial budaya dimana pribadi itu tinggal dan praktik profesi yang dilakukannya sehari-hari. Berkenaan dengan latar belakang anak, hasil penelitian ini sesuai dengan artikel tersebut. Hasil wawancara terhadap guru TK Islam Al Azhar 10 Serang mengenai program pembiasaan anak membaca dan meminjam buku di pusat sumber belajar TK Islam Al Azhar. Narasumber menyampaikan bahwa pelayanan peminjaman buku diberikan setiap hari sekolah. Berbeda dengan perpustakaan pada umumnya, peminjaman buku di PSB TK Islam Al Azhar 10 Serang dilakukan pada setiap pagi. Ibu Yusi sebagai pengelola PSB dibantu oleh setiap guru kelas berkeliling memasuki semua kelas untuk menanyakan dan menawarkan pada anak agar meminjam dan mengembalikan buku yang sudah dipinjam sebelumnya. Pembiasaan ini dilakukan sebelum anak-anak melakukan ikrar dan setelah ikrar sebelum anak memulai pembelajaran.

Selain hasil wawancara, peneliti juga memperoleh data melalui survei mengenai penggunaan kosa kata yang terdapat dalam kalimat dan paragraf yang disajikan dalam buku cerita di Pusat Sumber Belajar TK Islam Al Azhar 10 Serang dideskripsikan dalam Tabel 4.

Tabel 4. Kosakata Mudah Dipahami Anak

\begin{tabular}{cccccccc}
\hline Alternative Choice & $\mathrm{F}_{\mathrm{o}}$ & $\%$ & $\mathrm{~F}_{\mathrm{e}}$ & $\mathrm{F}_{\mathrm{o}}-\mathrm{F}_{\mathrm{e}}$ & $\left(\mathrm{F}_{\mathrm{o}}-\mathrm{F}_{\mathrm{e}}\right)^{2}$ & $\frac{\left(\mathrm{F}_{\mathrm{o}}-\mathrm{F}_{\mathrm{e}}\right)^{2}}{\mathrm{~F}_{\mathrm{e}}}$ & $\square{ }^{2}$ \\
\hline Sangat baik & 13 & 13.00 & 20 & -7 & 49 & 2.45 & 71.2 \\
Baik & 37 & 37.00 & 20 & 17 & 289 & 14.45 & \\
Cukup & 43 & 43.00 & 20 & 23 & 529 & 26.45 & $\mathrm{dk} 5-1$ \\
Kurang & 6 & 6.00 & 20 & -14 & 196 & 9.8 & $95 \%$ \\
Sangat Kurang & 1 & 1.00 & 20 & -19 & 361 & 18.05 & 9.49 \\
\hline Total & 100 & 100 & 100 & & & 71.2 & \\
\hline
\end{tabular}

Tabel 5. Kesesuaian Visual Literasi untuk Berbagai Karakter Siswa

\begin{tabular}{|c|c|c|c|c|c|c|c|}
\hline Alternative Choice & $\mathrm{F}_{\mathrm{o}}$ & $\%$ & $\mathrm{~F}_{\mathrm{e}}$ & $\mathrm{F}_{\mathrm{o}}-\mathrm{F}_{\mathrm{e}}$ & $\left(F_{o}-F_{e}\right)^{2}$ & $\frac{\left(F_{0}-F_{e}\right)^{2}}{F_{e}}$ & $\square^{2}$ \\
\hline Sangat baik & 12 & 12.00 & 20 & -8 & 64 & 3.2 & 60.5 \\
\hline Baik & 31 & 31.00 & 20 & 11 & 121 & 6.05 & \\
\hline Cukup & 44 & 44.00 & 20 & 24 & 576 & 28.8 & $\mathrm{dk} 5-1$ \\
\hline Kurang & 13 & 13.00 & 20 & -7 & 49 & 2.45 & $95 \%$ \\
\hline Sangat Kurang & 0 & 0.00 & 20 & -20 & 400 & 20 & 9.49 \\
\hline Total & 100 & 100 & 100 & & & 60.5 & \\
\hline
\end{tabular}


Dari Tabel 4 didapatkan hasil bahwa $\chi^{2}$ h $71.2>\chi^{2}$ t 9.49 dengan Dk 5 - 1 pada tingkat kepercayaan 95\%. Hal ini berarti terdapat perbedaan yang signifikan antara frekuensi yang diperoleh dengan frekuensi yang diharapkan. Sehingga dengan demikian dapat diinterpretasikan bahwa sebanyak 43\% (hampir setengahnya) buku cerita yang berada di TK Islam Al Azhar 10 Serang telah cukup sesuai visual/gambar yang disajikan dengan kosa kata yang terdapat dalam kalimat dan paragraf. Sementara 37\% (hampir setengahnya) buku cerita lainnya menunjukkan kosakata yang baik.

Visual literasi yang disajikan dalam sebuah buku cerita, harus memperhatikan kebutuhan dari berbagai karakteristik anak. Kesesuaian gambar dan strategi penyajian visual dengan berbagai karakter anak menjadi salah satu pembahasan penelitian ini karena penelitian terdahulu membuktikan bahwa gambar yang sesuai mampu memudahkan seorang anak mengingat dan mengenal seniman-seniman yang sering tampil di TV (Bransford, Brown, \& Cocking, 2000). Lebih lanjut disampaikan bahwa anak berkebutuhan khusus mampu menampilkan kemampuan mengingat dan mengenal tersebut lebih baik daripada orang dewasa yang tidak mendapatkan strategi penyajian visual.

Berdasarkan hasil penelitian, buku cerita di Pusat Sumber Belajar TK Islam Al Azhar 10 Serang berdasarkan indikator kesesuaian untuk berbagai jenis karakter siswa dideskripsikan dalam Tabel 5.

Dari Tabel 5 didapatkan hasil bahwa $\chi^{2}$ h $60.5>\chi^{2}$ t 9.49 dengan Dk 5 - 1 pada tingkat kepercayaan 95\%. Hal ini berarti terdapat perbedaan yang signifikan antara frekuensi yang diperoleh dengan frekuensi yang diharapkan. Sehingga dengan demikian dapat diinterpretasikan bahwa sebanyak $44 \%$ (hampir setengahnya) visual literasi buku cerita di Pusat Sumber Belajar TK Islam Al Azhar 10 Serang sudah cukup sesuai dengan berbagai karakter siswa (31\%) buku lainnya dinyatakan baik.

Untuk mengembangkan kemampuan visual literasi pada anak diperlukan per- lakuan dan pendampingan pada anak saat anak berinteraksi dengan gambar visual, baik melalui buku cerita maupun media lainnya. Saat mendampingi anak, orang tua, guru atau orang dewasa lainnya dapat mengajukan pertanyaan yang berkontribusi pada pemahaman anak-anak tentang aspek visual dari sebuah buku bergambar. Berikut adalah beberapa pertanyaan yang direkomendasikan oleh Stephenson (2014) dalam artikelnya yang berjudul Visual Literacy Through Children's Picture Books yang dapat membantu guru, orang tua dan orang dewasa lainnya mengenali kemampuan visual literasi pada anak yaitu sebagai berikut.

Pertama, What do you notice in the picture? Apa yang kamu perhatikan dari gambar ini? Melalui pertanyaan tersebut, pendamping bisa mendapatkan informasi mengenai pemahaman anak terhadap pesan suatu gambar. Kedua, Do the words exactly match what's happening in the illustration? Apakah kata-kata atau narasi ceritanya sama persis dengan apa yang terjadi dalam ilustrasi gambar. Saat anak menjawab pertanyaan tersebut, terjadi proses analisis dan sintesis atau high order thinking sehingga melatih kemampuan berpikir kritis anak.

Ketiga, How does that picture/color make you feel? Bagaimana perasaanmu terhadap gambar ini? Pertanyaan ini mengajarkan anak mengungkapkan perasaannya kepada orang lain. Ini perlu dilakukan agar perkembangan emosi anak lebih optimal dan sehat. Keempat, What does that image remind you of? Apakah gambar ini mengingatakanmu pada sesuatu? Kalimat tanya ini merujuk pada kemampuan anak menghubungkan masa lampau, melakukan asimilasi, evaluasi dan analisis peristiwa. Kelima, How has the illustration changed/progressed from this page to the next? Bagaimana perubahan gambar yang terjadi dari halaman yang ini dan halaman selanjutnya? Pertanyaan ini menunjukkan kemampuan menginterpretasikan dan membuat prediksi peristiwa yang akan datang sehingga dapat melakukan antisipasii sejak dini. 
Pendapat Stephenson mengenai hal ini menjadi rujukan penelitian yang mengumpulkan informasi mengenai keruntutan materi yang dikemas dalam sebuah cerita yang disajikan pada Tabel 6 .

Dari Tabel 6 didapatkan hasil bahwa $\chi^{2}$ h $68.3>\chi^{2}$ t 9.49 dengan Dk $5-1$ pada tingkat kepercayaan 95\%. Hal ini berarti terdapat perbedaan yang signifikan antara frekuensi yang diperoleh dengan frekuensi yang diharapkan. Sehingga dengan demikian dapat diinterpretasikan bahwa sebanyak $46 \%$ (setengahnya) visual literasi buku cerita di Pusat Sumber Belajar TK Islam Al Azhar 10 Serang memuat materi yang runtut dengan range cukup dan hampir setengahnya (31\%) juga dapat dinyatakan baik. Anak sebaiknya diajak dan dilibatkan saat guru atau orang tua bercerita, untuk memberikan prediksi visual yang akan tersaji pada halaman berikutnya.

Pertama, pertanyaan tentang Do the animals look real? Apakah gambar binatang ini tampak seperti binatang sesungguhnya?. Anak akan melibatkan pengalamannya dengan apa yang dilihatnya dalam buku cerita. Missal, seekor gajah memiliki pro- porsi tubuh yang sangat besar dengan bentuk hidung atau belalai yang sangat panjang. Anak yang pernah melihat gajah secara langsung di kebun binatang tentu dapat memberikan jawaban.

Berdasarkan hasil wawancara, diperoleh informasi bahwa buku cerita yang paling disukai dan paling sering dipinjam anak adalah fabel. Buku cerita yang menyajikan gambar binatang cenderung diminati anak karena ilustrasi yang disajikan lebih menarik karena dikemas dalam bentuk karikatur.

Saat bercerita, guru hendaknya memperhatikan tujuan pembelajaran yang didesain sebelumnya. Jika tema yang diusung pada hari guru bercerita bukan tentang binatang, maka hendaknya guru menyediakan buku-buku yang relevan dengan kebutuhan pembelajaran.

Berdasarkan hasil penelitian, kesesuaian visual yang disajikan dalam buku cerita di Pusat Sumber Belajar TK Islam Al Azhar 10 Serang dengan tujuan pembelajaran dideskripsikan sebagaimana disajikan pada Tabel 7.

Tabel 6. Urutan Materi

\begin{tabular}{cccccccc}
\hline Alternative Choice & $\mathrm{F}_{\mathrm{o}}$ & $\%$ & $\mathrm{~F}_{\mathrm{e}}$ & $\mathrm{F}_{\mathrm{o}}-\mathrm{F}_{\mathrm{e}}$ & $\left(\mathrm{F}_{\mathrm{o}}-\mathrm{F}_{\mathrm{e}}\right)^{2}$ & $\frac{\left(\mathrm{F}_{\mathrm{o}}-\mathrm{F}_{\mathrm{e}}\right)^{2}}{\mathrm{~F}_{\mathrm{e}}}$ & $\square^{2}$ \\
\hline Sangat baik & 8 & 8.00 & 20 & -12 & 144 & 7.2 & 68.3 \\
Baik & 31 & 31.00 & 20 & 11 & 121 & 6.05 & \\
Cukup & 46 & 46.00 & 20 & 26 & 676 & 33.8 & $\mathrm{dk} 5-1$ \\
Kurang & 15 & 15.00 & 20 & -5 & 25 & 1.25 & $95 \%$ \\
Sangat Kurang & 0 & 0.00 & 20 & -20 & 400 & 20 & 9.49 \\
\hline Total & 100 & 100 & 100 & & & 68.3 & \\
\hline
\end{tabular}

Tabel 7. Kesesuaian dengan Tujuan Pembelajaran

\begin{tabular}{ccccccccc}
\hline Alternative Choice & $\mathrm{F}_{\mathrm{o}}$ & $\%$ & $\mathrm{~F}_{\mathrm{e}}$ & $\mathrm{F}_{\mathrm{o}}-\mathrm{F}_{\mathrm{e}}$ & $\left(\mathrm{F}_{\mathrm{o}}-\mathrm{F}_{\mathrm{e}}\right)^{2}$ & $\frac{\left(\mathrm{F}_{\mathrm{o}}-\mathrm{F}_{\mathrm{e}}\right)^{2}}{\mathrm{~F}_{\mathrm{e}}}$ & $\square^{2}$ \\
\hline Sangat baik & 15 & 15.00 & 20 & -5 & 25 & 1.25 & 46.1 \\
Baik & 40 & 40.00 & 20 & 20 & 400 & 20 & \\
Cukup & 29 & 29.00 & 20 & 9 & 81 & 4.05 & $\mathrm{dk} 5-1$ \\
Kurang & 16 & 16.00 & 20 & -4 & 16 & 0.8 & $95 \%$ \\
Sangat Kurang & 0 & 0.00 & 20 & -20 & 400 & 20 & 9.49 \\
\hline Total & 100 & 100 & 100 & & & 46.1 & \\
\hline
\end{tabular}


Dari Tabel 7 didapatkan hasil bahwa $\chi^{2}{ }_{\mathrm{h}} 46.1>\chi^{2} \mathrm{t} 9.49$ dengan Dk 5 - 1 pada tingkat kepercayaan 95\%. Hal ini berarti terdapat perbedaan yang signifikan antara frekuensi yang diperoleh dengan frekuensi yang diharapkan. Sehingga dengan demikian dapat diinterpretasikan bahwa sebanyak $40.00 \%$ (hampir setengahnya) buku cerita yang berada di TK Islam Al Azhar 10 Serang berada dalam kondisi baik dalam hal tingkat kesesuaian dengan tujuan pembelajaran dan $29 \%$ buku cerita lainnya berada dalam kondisi cukup. Artinya penyediaan buku cerita dengan berbagai tema dipandang cukup beragam memberikan alternatif pilihan bagi pembaca.

Pertama, why does the cat look sad? Mengapa kucing nampak sedih? Pertanyaan ini melatih anak untuk mengembangkan sikap empati terhadap orang lain.

Kedua, whose perspective is this illustration from? Sudut pandang siapa yang diceritakan dalam ilustrasi ini? Nilai-nilai yang diajarkan melalui pertanyaan ini yaitu anak belajar memahami karakter orang lain sehingga menumbuhkan sikap toleran terhadap pandangan hidup atau pendapat orang lain.

Ketiga, how do you think the artist made these illustrations? Menurutmu, bagaimana artis membuat ilustrasi ini? Anakanak diajarkan untuk menganalisis proses yang harus ditempuh untuk menghasilkan suatu karya sehingga anak lebih menghargai lingkungan sekitarnya serta menjaganya dari kerusakan.

Keempat, why did the artist choose those colors, and why do they change here? Mengapa artis memilih warna itu, dan mengapa mereka memilih warna yang berbeda di halaman lainnya?. Biasanya illustrator gambar buku cerita memilih pewarnaan yang berbeda pada gambar yang disajikan di setiap halaman. Hal ini dikarenakan gambar yang divisulisasikan harus disesuaikan dengan narasi cerita yang terdapat pada halaman tersebut. Setiap halaman pada buku cerita memiliki pesan yang berbeda. Selain itu terdapat bahasa pengantar pada awal halaman buku cerita, hingga terjadi klimak dan anti klimak pada alur cerita yang disampaikan. Juga terhadap karakter penokohan yang ingin disampaikan illustrator melalui pemilihan warna yang sesuai dengan karakter tokoh pada gambar yang disajikan.

Buku cerita memiliki kekuatan, yakni dapat menyampaikan prediksi atau perkiraan peristiwa yang akan terjadi di masa datang. Anak diajak menafsirkan gambar dan memprediksi apa yang akan terjadi selanjutnya berdasarkan rangkaian ilustrasi gambar yang disusun oleh illustrator. Menurut Storey (1984), “There are many picture books which are useful when teaching prediction of story events or endings from the illustrations". Pernyataannya ini senada dengan hasil temuan penelitian visual literasi buku cerita anak. Peneliti mengumpulkan data mengenai susunan gambar dan materi yang berurutan sesuai alur naskah cerita dan hasil yang ditunjukkan adalah cukup.

Tidak terbantahkan lagi bahwa visual literasi harus menjadi perhatian banyak pihak, baik guru, orang tua, ahli bahasa, pengembang media, illustrator dan semua pihak yang terlibat dalam penyajian buku cerita yang dapat menyampaikan pesan yang sangat jelas dan dipahami oleh anak dengan baik. Sendak sebagai pakar visual menyatakan dalam wawancaranya bersama Kunze bahwa, "we work to bring pictures and words together to achieve a wholeness" - Maurice Sendak (Kunze, 2016). Merujuk pada pernyataan ini, diharapkan penelitian ini memberikan kontribusi bagi pengembangan media buku yang menyajikan visual literasi.

\section{Simpulan}

Berdasarkan hasil pengumpulan, pengolahan dan analisa data tentang Visual Literacy Media Pembelajaran Buku Cerita Anak, maka dapat diambil kesimpulan bahwa pada umumnya visualisasi gambar yang disajikan dalam buku cerita di Pusat Sumber Belajar (PSB) TK Islam Al Azhar 10 Serang telah menunjukkan hasil yang cukup dengan frekuensi kemunculan rata-rata 
hampir setengahnya. Hal ini dibuktikan dengan penyebaran angket dan wawancara Kualitas gambar visual disajikan dengan sangat baik, Kesesuaian visual literasi dengan tujuan pemelajaran, kesesuaian materi dengan gambar yang disajikan, daya tahan buku, kecepatan presentasi materi, disajikan dengan baik dan indikator lainnya menunjukkan hasil yang cukup. Indikator tersebut yaitu kosakata mudah dipahami anak, penggunaan bahasa yang singkat, padat dan jelas, urutan dan runtut materi, kesesuaian penyajian visual dengan kebutuhan berbagai karakter siswa, prosedur penggunaan, penyajian pedoman untuk guru. Ini menunjukkan hasil yang belum optimal. Oleh karena itu peneliti merekomendasikan perlu dilakukannya penelitian lebih mendalam terhadap in-dikator tersebut.

Selain itu peneliti juga menyarankan pada beberapa pihak yang terlibat baik langsung maupun tidak langsung dalam penelitian ini, sebagai berikut.

Pertama, bagi guru, hendaknya memahami fungsi dari gambar yang disajikan dalam buku cerita dan menggunakan tehnik bercerita yang kreatif serta lebih taat pada prosedur dan pedoman yang berlaku.

Kedua, bagi editor, illustrator, dan penerbit buku, agar lebih memperhatikan kualitas gambar atau visual sesuai dengan latar belakang sosial dan budaya serta peranannya dalam menyajikan materi pada anak.

Ketiga, bagi peneliti selanjutnya, penelitian dapat dikembangkan dengan melakukan penelitian dengan faktor-faktor dan aspek-aspek yang lebih khusus dan populasi yang lebih representatif.

\section{Daftar Pustaka}

Bransford, J. D., Brown, A. L., \& Cocking, R. R. (2000). How people learn: brain, mind, experience and school. Washington, D.C.: National Academy Press. https://doi.org/10.17226/9853

Fatimah, A. (2016). Parent's visual literacy toward toys symbol. In Internatinal Conference The 3rd Semarang Early Childhood Research and Education Talks. Semarang State University.

Kunze, P. C. (2016). Conversations with Maurice Sendak. Mississippi: Univ. Press of Mississippi.

Shambaugh, N., \& Beacham, C. (2017). Visual guidebooks: documenting a personal thinking language. Journal of Visual Literacy, 36(1), 1-19. https:// doi.org/10.1080/1051144X.20 17.1291779

Stephenson, S. (2014). Visual literacy through children's picture books. Retrieved April 24, 2017, from https://www.scholastic.com/parents /school-success/learning-toolkitblog/visual-literacy-throughchildrens-picture-books.html

Storey, D. C. (1984). Reading comprehension, visual literacy and picture book illustrations. Reading Horizons, 25(1), 54-59.

Sudjana, N., \& Ibrahim. (2001). Penelitian dan penilaian pendidikan. Bandung: Sinar Baru Algensindo. 